\title{
PHYLOGENETIC ANALYSIS OF THE ANDEAN GENUS BRACHYCLADIUM LUER (SYN. OREOPHILUS HIGGINS \& ARCHILA) AND CLOSELY RELATED GENERA BASED ON NUCLEAR ITS SEQUENCING
}

\author{
MARK WILSON ${ }^{1,3} \&$ LOU JOST ${ }^{2}$ \\ ${ }^{1}$ Biology Department, The Colorado College, Colorado Springs, CO 80903, USA \\ ${ }^{2}$ Via a Runtun, Baños, Tungurahua, Ecuador \\ ${ }^{3}$ Corresponding author: mwilson@coloradocollege.edu
}

We previously reported that nrITS sequencing and phylogenetic analysis revealed at least four cryptic species within Brachycladium nummularium (syn. Oreophilus nummularius). Sequencing of additional species in the genus revealed two major clades within Brachycladium, the "nummularium"-complex plus B. stalactites and Luer's section Amplectentes. Since the relationship of Brachycladium to Andinia had been noted earlier, a number of Andinia species were also included. Two clades were observed, a clade containing A. lappacea, A. pensilis, and $A$. vestigipetala that was closely related to Brachycladium and a second, more distantly related clade containing A. dalstroemii, A. pogonion, and A. schizopogon.
Samples of two additional genera, Masdevalliantha Szlachetko \& Margonska and Xenosia Luer, were included in the analysis based upon morphological similarity to Andinia. These two genera formed a clade that was sister to both Brachycladium and Andinia. Only the node subtending clades of all four genera had a high level of bootstrap support, whereas nodes subtending clades of Brachycladium plus Andinia, or Brachycladium alone, had much lower support. If future chloroplast sequencing produces phylogenies congruent with nrITS, this would indicate that Andinia, Brachycladium (syn. Oreophilus), Masdevalliantha, and Xenosia should all be placed in the same genus. 